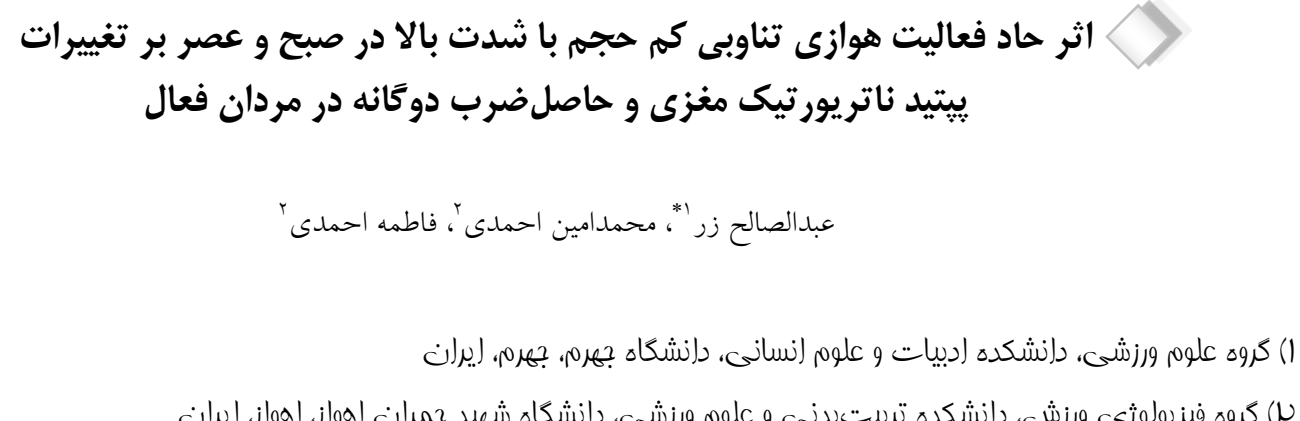

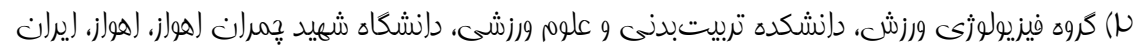

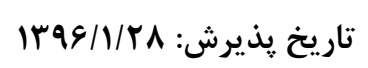

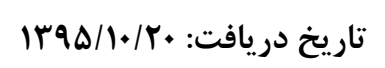

\begin{abstract}
جَكيده

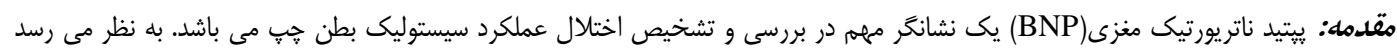

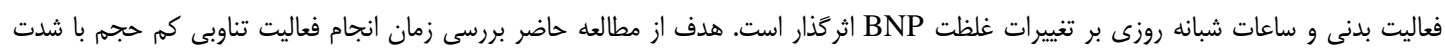

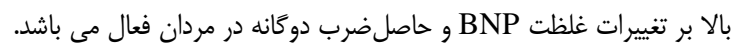

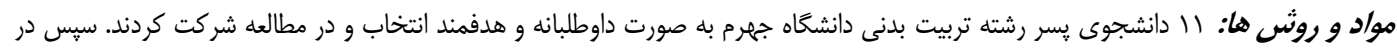

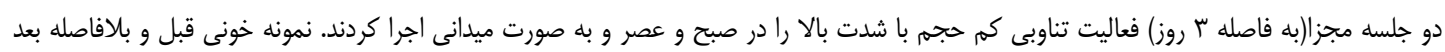

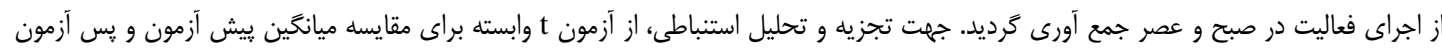

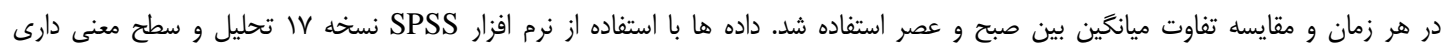
P<0.05 در نظر كرفته شده بود.

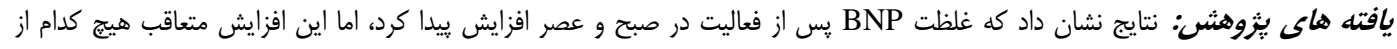

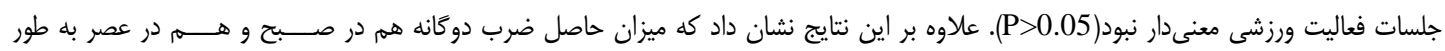

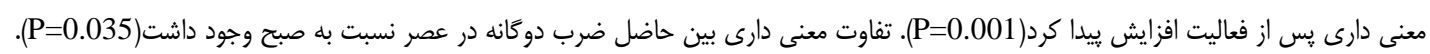

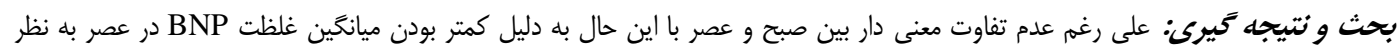

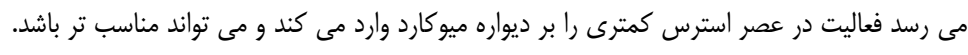

وازه هاى كليدى: يِتيد ناتريورتيك مغزى، حاصل ضرب دوگانه، فعاليت هوازى تناوبى

* *ويسنده مسئول: گروه علوم ورزشى، دانشكده ادبيات و علوم انسانى، دانشكاه جهرم، جهرم، ايران

Email:salehzar@gmail.com

Copyright (C) 2018 Journal of Ilam University of Medical Science. This is an open-access article distributed under the terms of the Creative Commons Attribution international 4.0 International License (https://creativecommons.org/licenses/by-nc/4.0/) which permits copy and redistribute the material, in any medium or format, provided the original work is properly cited. 
تفريحى ورزش مى كنند به ويزه بعد از جلسات تمرين

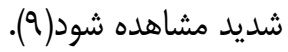

حاصل ضرب دو كانه شاخصى است كه همبستخى

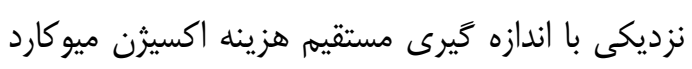

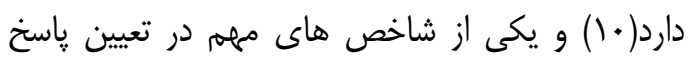

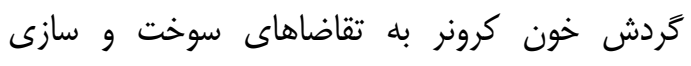

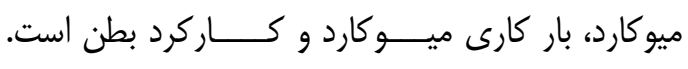

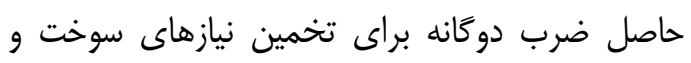

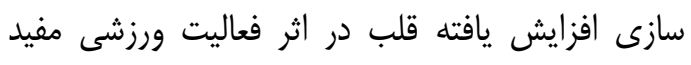

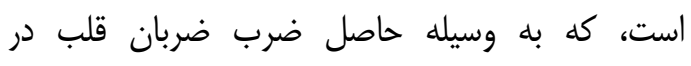

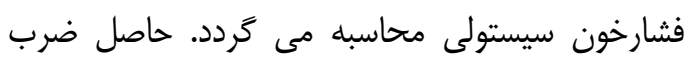

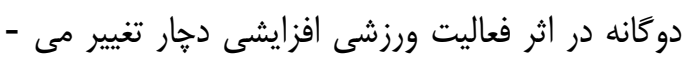

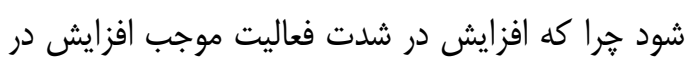

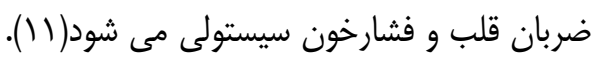

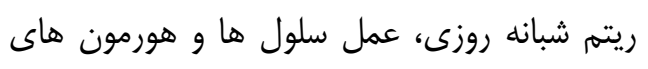

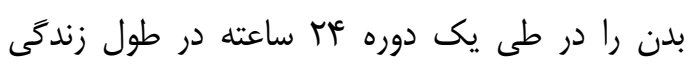

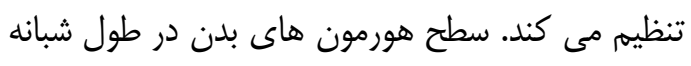
روز در نوسان است؛ از اين رو بررسى تاثير ريتم شبانه

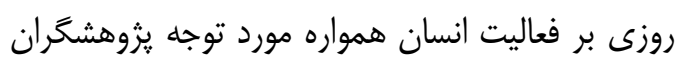

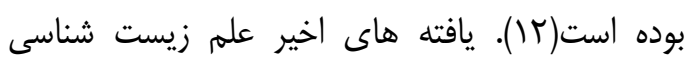

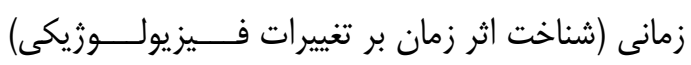

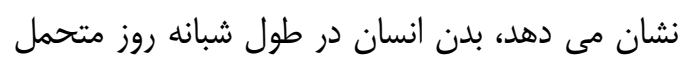

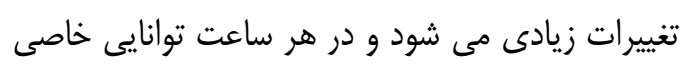
دارد. به نظر مى رسد ساعات شبانه رئه روزى بر بر تغييرات

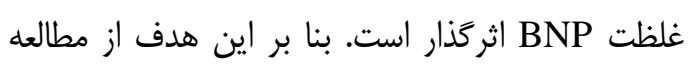

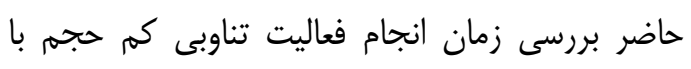

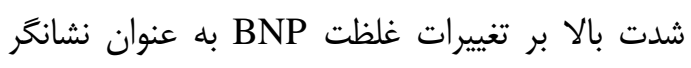

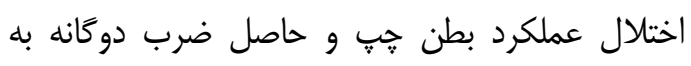
عنوان شاخص بار كارى ميوكارد و كاركرد بطن دي درل مردان فعال بود.

\section{مواد و روش هان في بود}

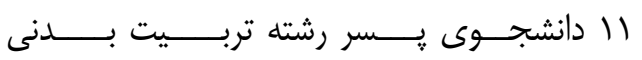

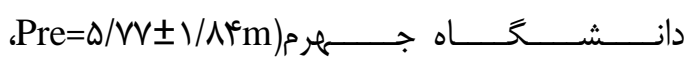

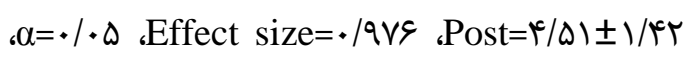

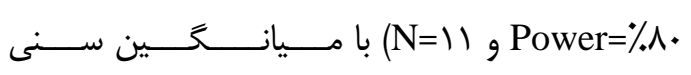

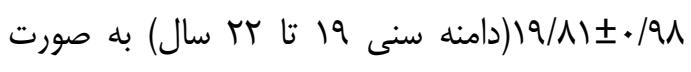

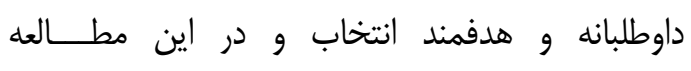
شـركت

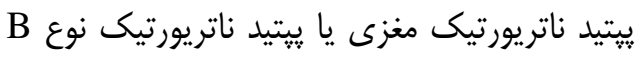

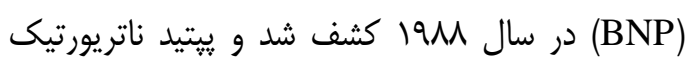

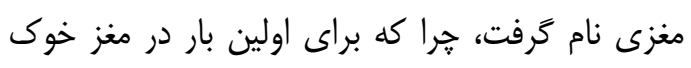

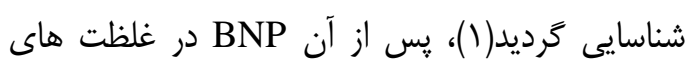

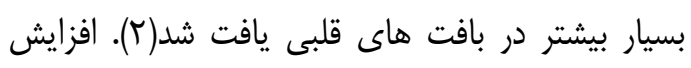

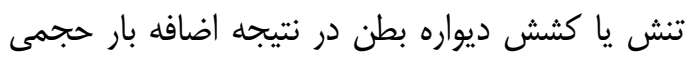

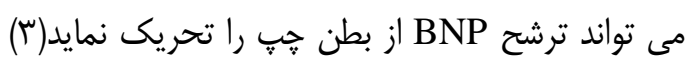

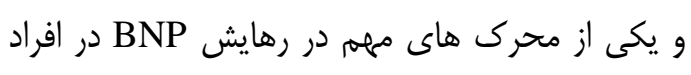

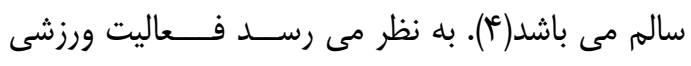
مى تواند غلظت سرمى اين يِيتيد را تحت تاثير قرار

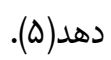

امروزه اشكال جديد و متنوعى از تمرينات ورزشى دهى در حال توسعه هستند و به طور معمول مورد استفاده

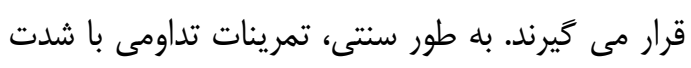
متوسط روش تمرينى ترجيحى در دستيابى به تغييرات

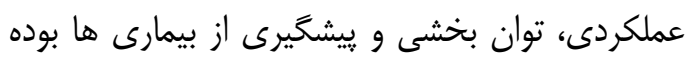

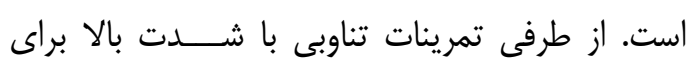

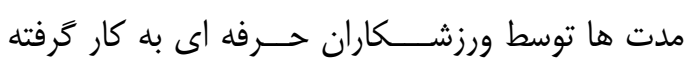
مى شد، اما به عنوان يك روش تمات تمرينى موثر همانند تمرينات سنتى، كمتر در جوامع علمى مورد توجه قرار

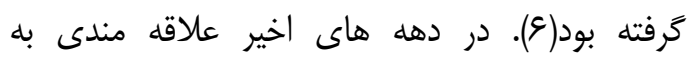
تمرينات تناوبى با شدت بالا افزايش يافته است. اين إند

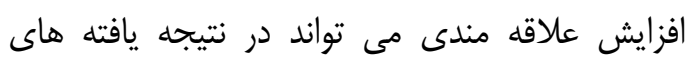

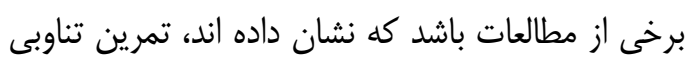

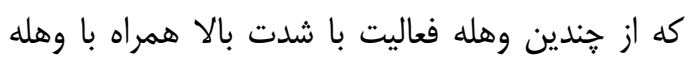

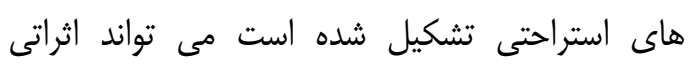

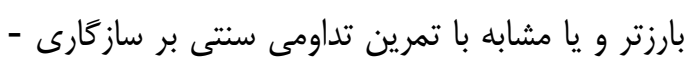

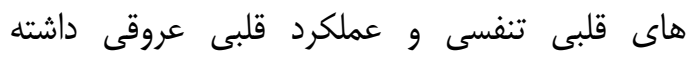

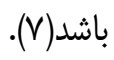
علاوه بر اين دوهاى سرعت متوالى در ورزش هاى تيمى بسيار رايج است و به طور قابل توجهى مى تواند به عملكرد ورزشى و آمادخى هوازى ساير فعاليت ها نيز كمى كند. اما، با توجه به اين كه BNP به به لهائ لحاظ

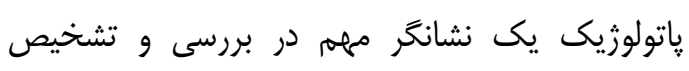

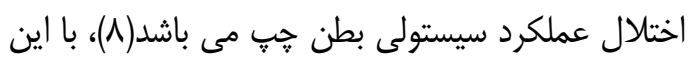

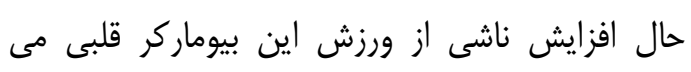

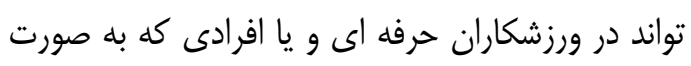


برَشت •r متر با حداكثر سرعت در يك مسافت مترى بود كه مسير تمرين توسط سه مخروط مشخص شده بود. در اين يروتكل آزمودنى ها در ابتدا از نقطه

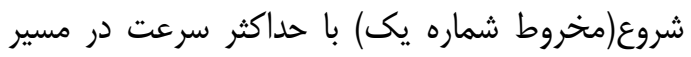

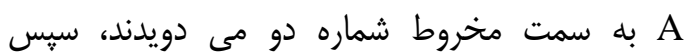
برگشته و مسير •r مترى B را به طرف مخروط شماره ب مى دويدند و در نهايت در مسير C به سمت نقطه

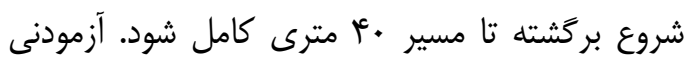
ها اين كار را به صورت متوالى و با حداكثر سرعت در

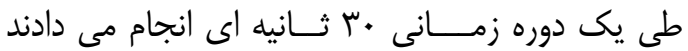

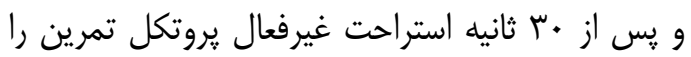

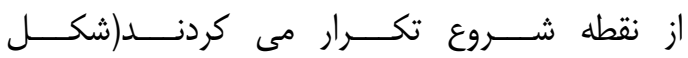

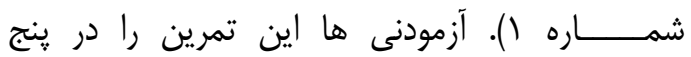

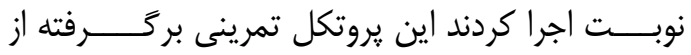

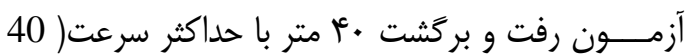
(m maximal shuttle run test مطالــــات مختلف به عنوان فعاليت تناوبى با شدت

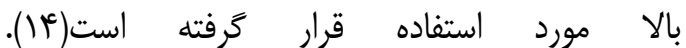

كردند. در ابتداى مطالعه آزمودنى ها از اهداف و

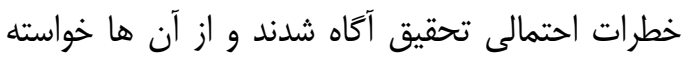

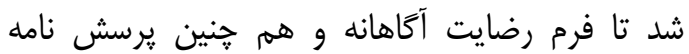
سابقه يزشكى شركت در طرح يزوهشى را با با دقت

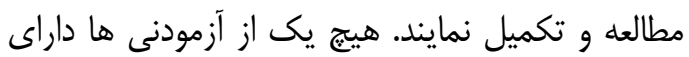
سابقه بيمارى ريوى، كليوى، قلبى-عروقى يا ديابت نبودند و مشروبات الكلى و سيكار استعمال نمى كردند. در جلسه اى مجزا قد و وزن آزمودنى ها با استفاده از ترازو و قدسنج Seca 700 ساخت آلمان و تركيب بدنى دونى و درصد جربى بدن شركت كنندكان نيز به روشان مقاومت و هدايت يذيرى الكتريكى با استفاده از دستخاه بيواميدنس(BoCA X1, Medigate, Korea) اندازه گيرى گرديد(سا) و با نحوه اجراى يروتكل فعاليت ورزشى آشنا شدند. سيس در دو جلسه مجزا فعاليت تناوبى با شدت بالا و حجم كم را در صبح|•

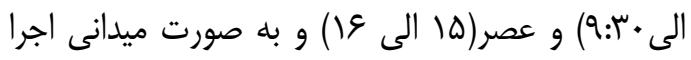
كردند. دو جلسه تجربى به وسيله سّروز دورها از هم جدا شده بودند. فعاليت تناوبى كم حجم با شدت

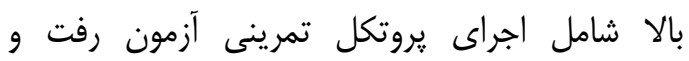

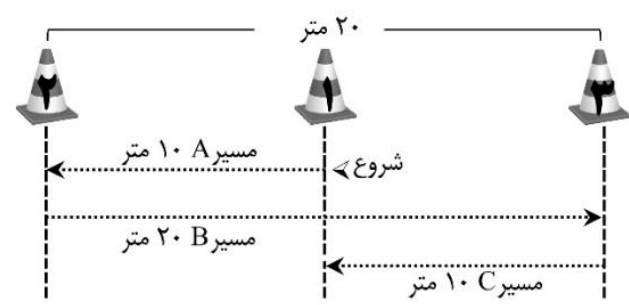

شكل شماره (. طرح شماتيك يروتكل فعاليت تناوبى كم حجم با شدت بالا

گيرى هاى بدنى، قبل و بلافاصله بعد از اجراى فعاليت

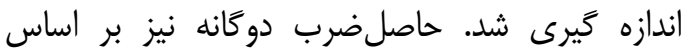
فرمول زير محاسبه كرديد(•) (1): (ميلى متر جيوه)فشارخون سيستولى ×(ضربه در درد دقيقه)ضربان قلب=حاصل ضرب دوكانه ه ميلى ليتر نمونه خونى قبل و بلافاصله

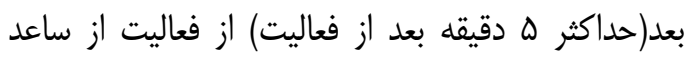

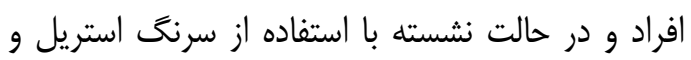

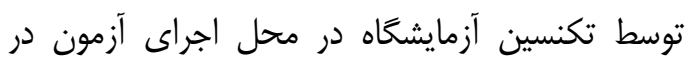

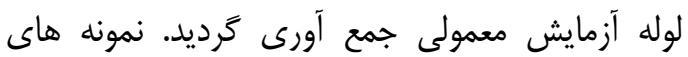

براى تعيين شدت فعاليت در اين مطالعه از ضربان

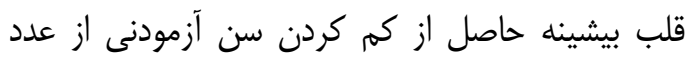

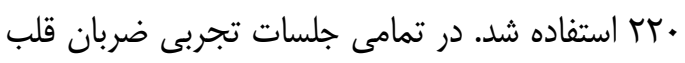

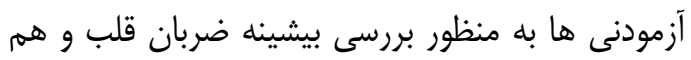
جنين ميانگين شدت در طى فعاليت تناوبى با شدت بالا، از ضربان سنج يلار) (FT4, Polar, China)

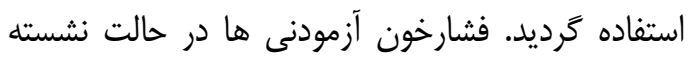

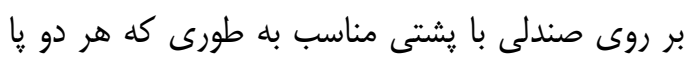
بر روى زمين قرار داشت به وسيله دستخاه فشارسنج بازويى ديجيتال(Omron M2, Kyoto, Japan) بر فر فران طبق راهنماى سازمان جهانى بهداشت براى اندازه - 
يافته هاى يزوهش

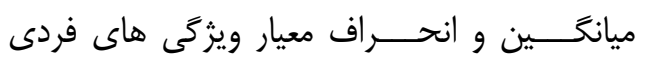

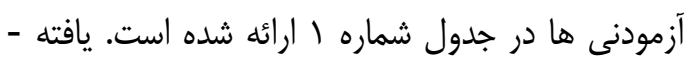
هاى مربوط به تغييرات BNP و حاصل ضرب دون دونانه در دو نوبت صبح و عصر در ييش آزمون و يس آز آزمون

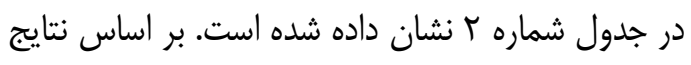

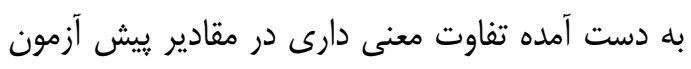

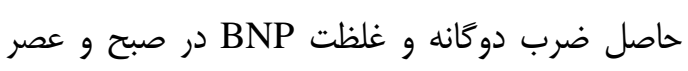

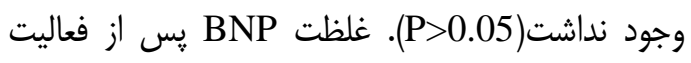

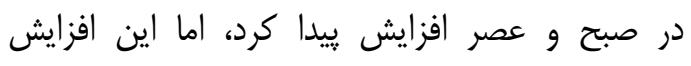
متعاقب هيج كدام از جلسات فعاليت ورزشى معنى دار دار

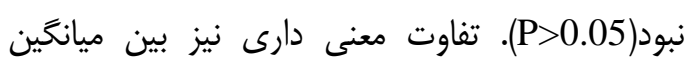
غلظت BNP در يس آزمون صبح و عصر مشاهده نغرديد(P>0.05)(نمودار شماره ()). علاوه بر اين نتايج

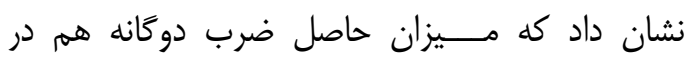

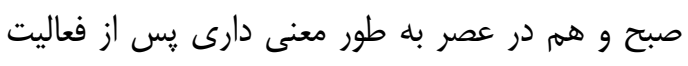

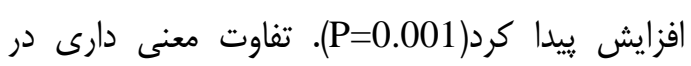
عس آزمون حاصل ضرب دوكانه بين فعاليت در صبح و

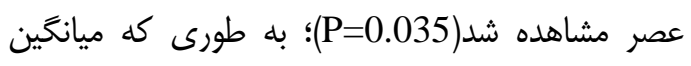
حاصل

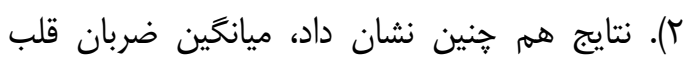
حين فعاليت به طور معنى دارى در عصر بيشتر از

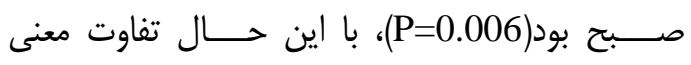
دارى در بيشينه ضربان قلب فعاليت در صبح و عصر بإن وجود نداشت(P>0.05).
جمع آورى شده به سرعت جهت تجزيه و تحليل به آزمايشگاه منتقل شدند.

به منظور اندازه كيرى غلظت سرمى BNP، در ابتدا

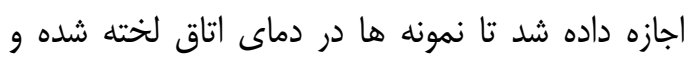

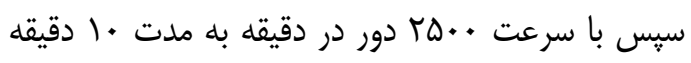

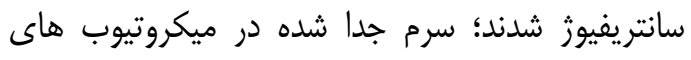

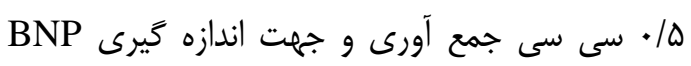

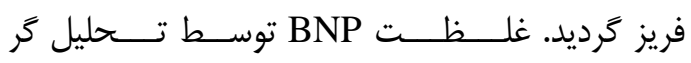
الايزا (Awareness Technology, Inc, USA) و وبا استفاده از كيت الايزا|| الايزا

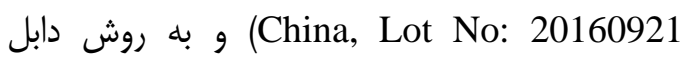
ساندويج الايزا اندازه گيرى شد. دامنه تشخيصى اين

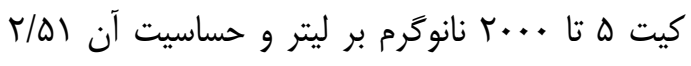

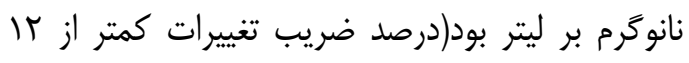
درصد).

از ميانگين و انحراف معسيار براى توصـــــف آمارى

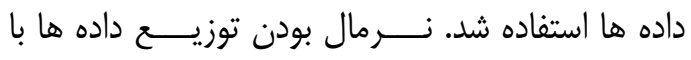

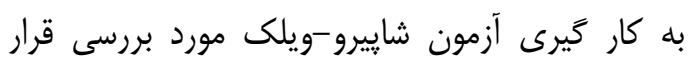

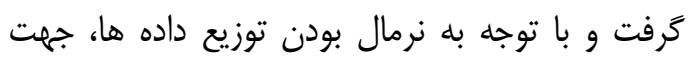

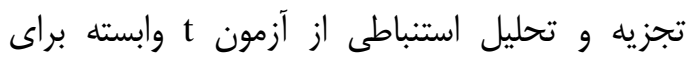

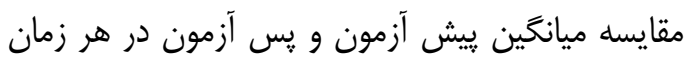

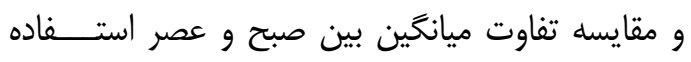
و سطــح معنى دارى P>0.05 در نظر كرفتله شد.

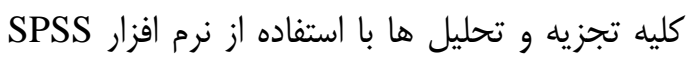

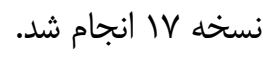

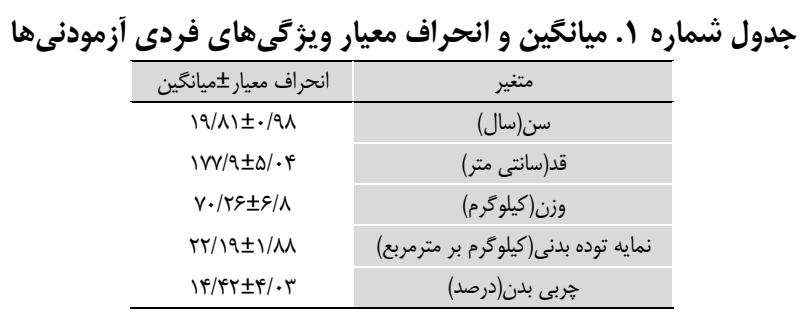

\begin{tabular}{|c|c|c|c|c|c|}
\hline \multicolumn{4}{|c|}{ زمان فعاليت } & \multirow{3}{*}{ اندازه كيرى } & \multirow{3}{*}{ متغيرها } \\
\hline \multicolumn{2}{|r|}{ عصر } & \multicolumn{2}{|r|}{ صبح } & & \\
\hline $\mathrm{P}$ & انحراف معيار \ميانگين & $P$ & انحراف معيار \ميانكين & & \\
\hline \multirow{2}{*}{. $K F$} & $|f / 99 \pm 1 / \Delta|$ & \multirow{2}{*}{$\cdot / r V$} & $\mid F / \Delta \Delta \pm 1 / 9 T$ & ييش آزمون & \multirow{2}{*}{$\begin{array}{l}\mathrm{BNP} \\
(\mathrm{ng} / \mathrm{L})\end{array}$} \\
\hline & $\mid Q / 4 Y \pm 1 / 9 q$ & & $|V / \varepsilon| \pm N / V \Delta$ & مِّ آزمون & \\
\hline \multirow{2}{*}{$\cdot / . \cdot 1 *$} & $99 \% r / \wedge) \pm \mid 9 / \% / \Delta 9$ & \multirow{2}{*}{$\cdot \mid \cdot \cdot * *$} & $q \uparrow \cdot \Delta / q \pm 1 \cdot r \Delta / v q$ & ييش آزمون & حاصل ضرب دوكانه \\
\hline & $\mid \Lambda r \cdot \Gamma \pm T \cdot \Lambda \Delta / \Delta \Delta$ & & $1 s V+q \pm r|V| \Delta s$ & ي پِ آزمون & (mmHg.bpm) \\
\hline
\end{tabular}




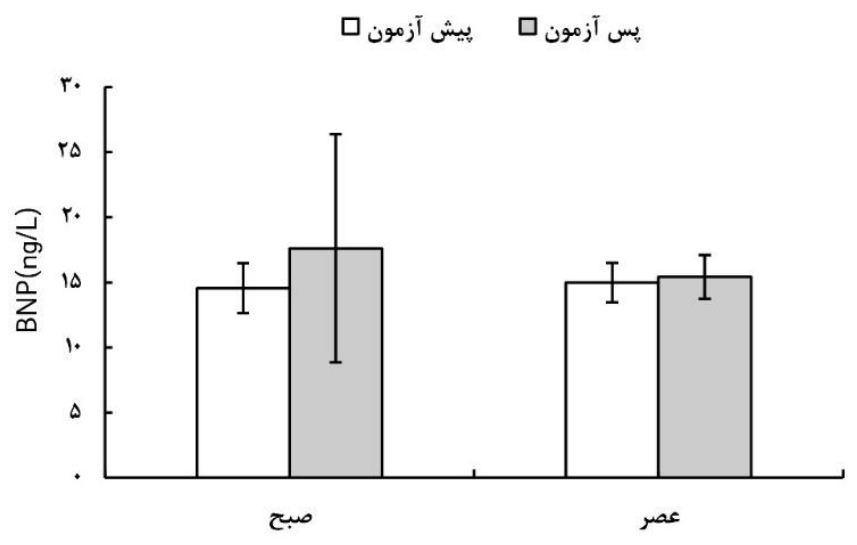

نمودار شماره (. ميانكَين و انحراف معيار غلظت BNP در بيش آزمون و يس آزمون به تفكيك صبح و عصر

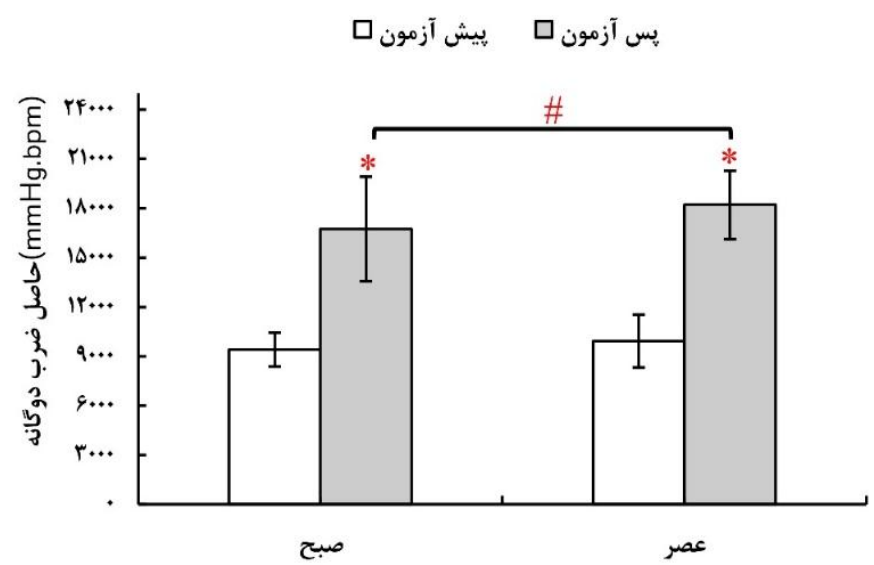

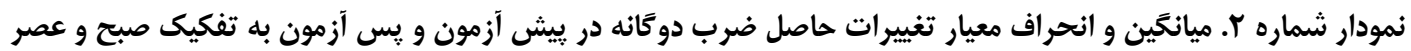

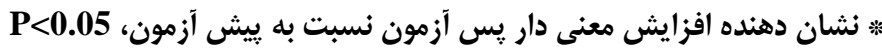

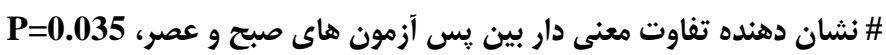

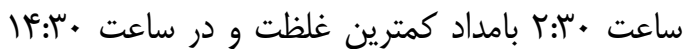
بيشترين غلظت را داشت. بر اساس اين يافـتهـه به نظر مى رسد غلظت BNP تا حدودى تحت تاثير ريتم شبانه روزى قرار دارد(ع). (1). نتايج مطالعه حاضر نشان داد كه افزايش در غلظت

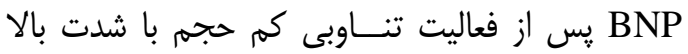

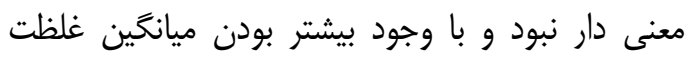

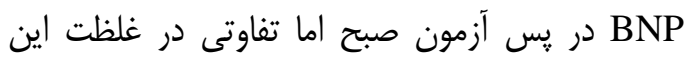
يِيتيد بين مقادير صبح و عصر وجود ندار نداشت. نتايج

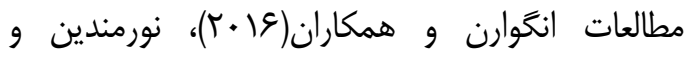

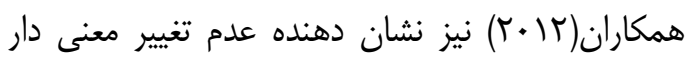

\section{بحث و نتيجه كَيرى}

تقريباً تمام فرآيندهاى فيزيولوزيكى و بيوني بدن انسان از ريته شبانه روزى ييروى مى كنند. نتايج

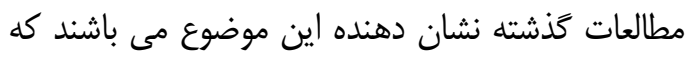

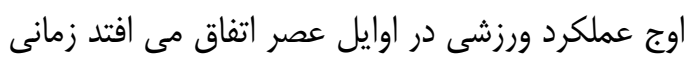

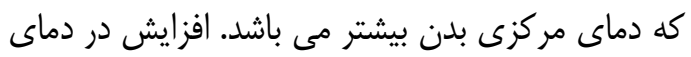
مركزى بدن موجب افزايش سوخت و ساز انرزى، بهبود برد

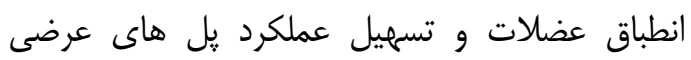
اكتين و ميوزين مى شود(ها). علاوه بر اين، اوهنو و

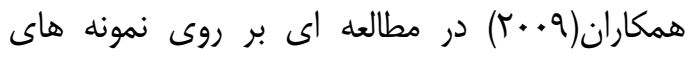

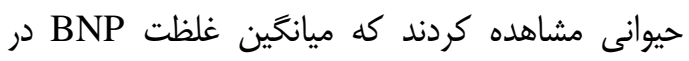


تنش يا كشش ديواره بطن در اثر اضافه بار حجمى مى

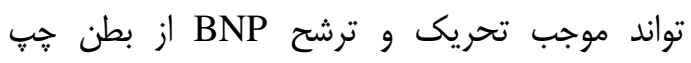

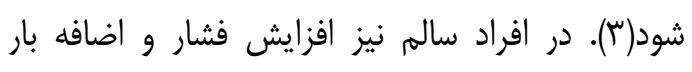

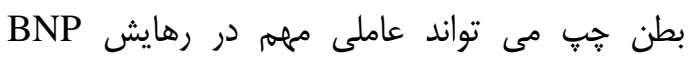

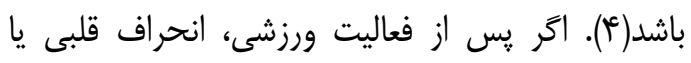

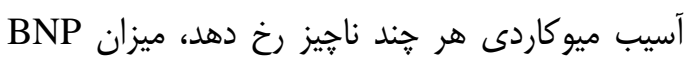

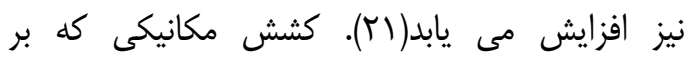
كارديوميوسيت وارد مى شود به سنسورهاى مكابئ مانيكى درون سلول منتقل شده و موجب تحريك و افزايش ماردي

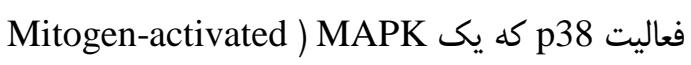
است مى شود. افزايش فعاليت (protein kinases

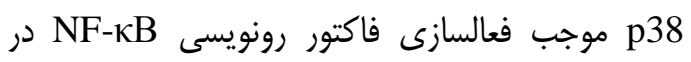
سيتويلاسم و جا به جايى آن به درون هسته مى شودا رودي در درون هسته به توالى DNA-kB mRNA را رونويسى مى كند preproBNP mRNA رونويسى شده از هسته سلول خارج و در سيتويلاسم

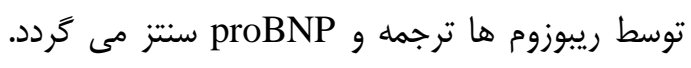
سيس proBNP توسط آنزيم فورين به دو زير واحد

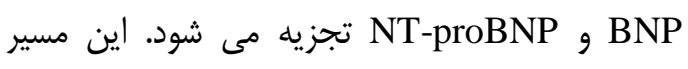

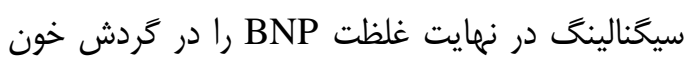
افزايش مى دهد(آب). از اين رو، از آن جايى كه افزايش غلظت BNP در خون بازتابى از افزايش تنش دئ ديواره ميوكارد به علت كشش كارديوميوسيت ناشى از اضافه

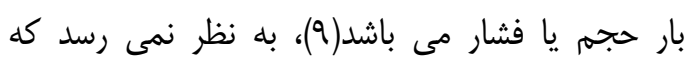

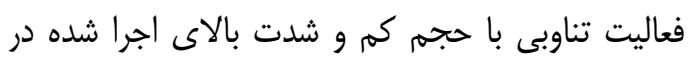

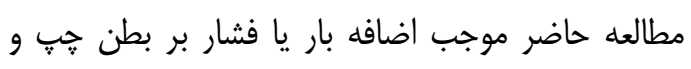

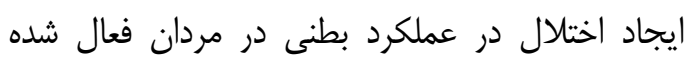

باشد.

يافته ها هم هنين نشان إنهان داد كه حاصل ضرب

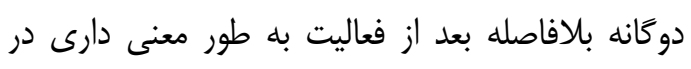

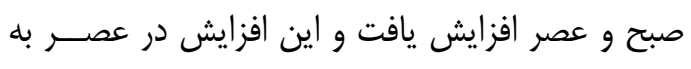

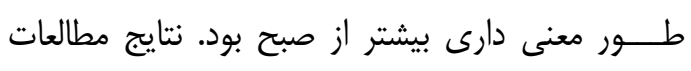

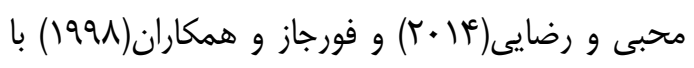

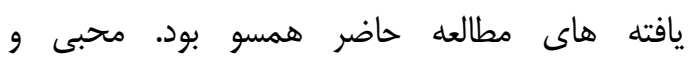

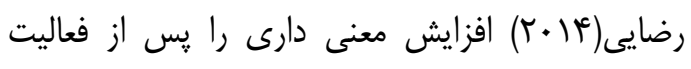

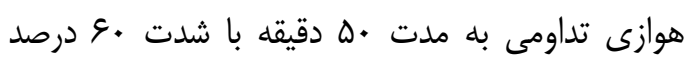

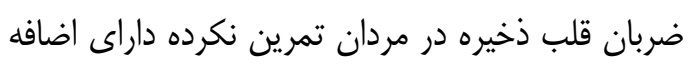
وزن گزارش كردند(هآ). با اين حال در تضاد با نتـــايج
BNP

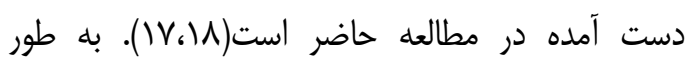

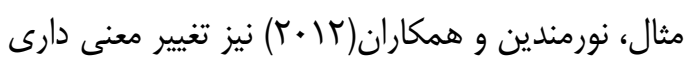

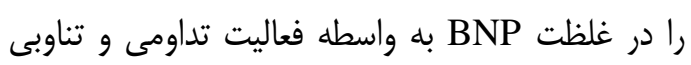
در بيماران با نارسايى قلبى مشاهده نكردند(N|). با اين

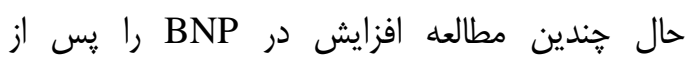

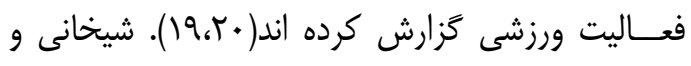

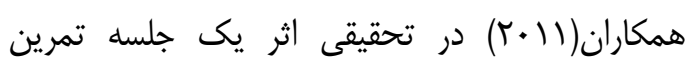

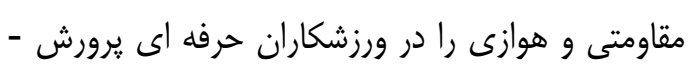

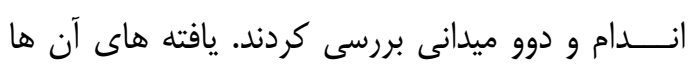

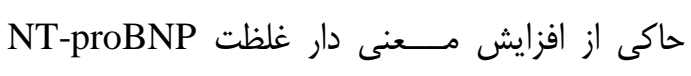

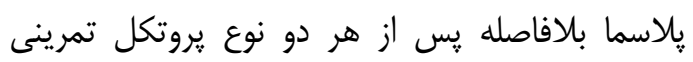

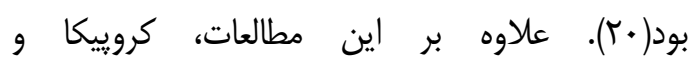

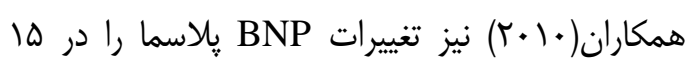

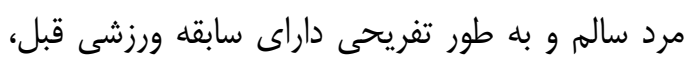

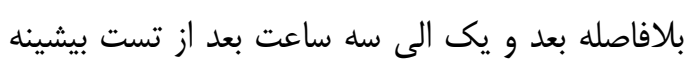

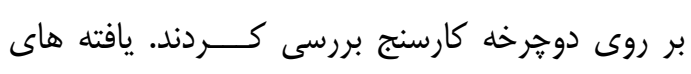
آن ها نشان داد كه افزايش در BNP تنها داريج بلافاصله بعد بردي از فعاليت بيشينه در مقايسـسه با مقادير ييش آز آزمون

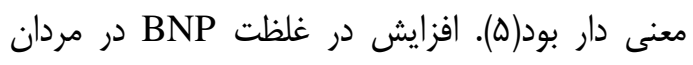

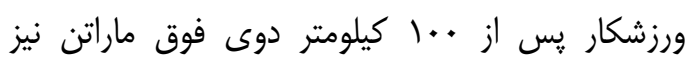

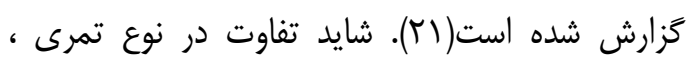

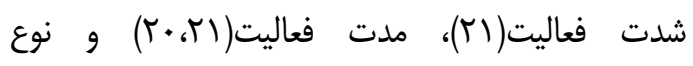

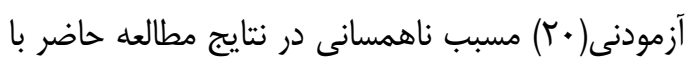

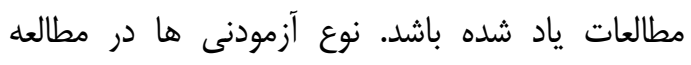

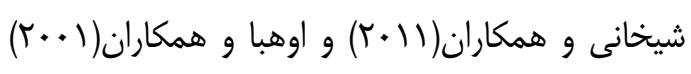
به ترتيب ورزشكاران حرفه ایى و تمرين كرده استقامتى ودمان بودند كه اين خود مى تواند عاملى در معنى دار شدن افزايش غلظت BNP در مطالعه آن ها باشد؛ زيرا به دانه

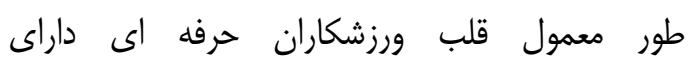

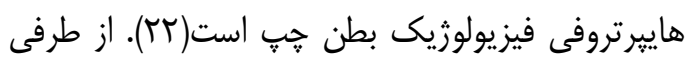

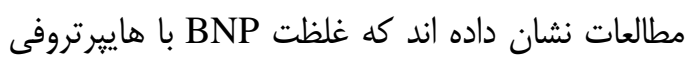

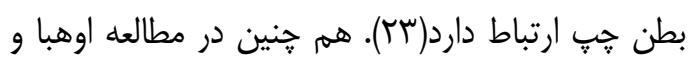

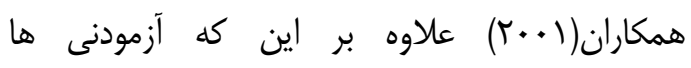

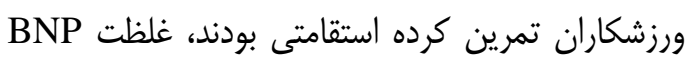

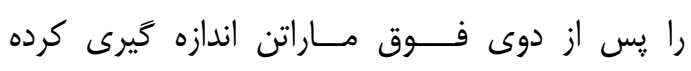

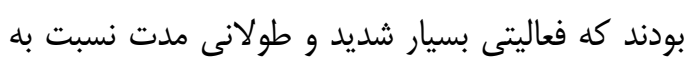

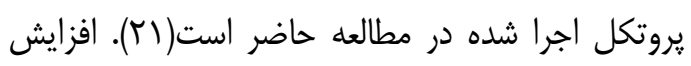


فعاليت بدنى متناسب با افزايش شدت فعاليت، ميزان

$$
\text { تحريك عصب سمياتيـى }
$$

افزايش وييدا مى كند. اين تحريكات در طى فعاليت

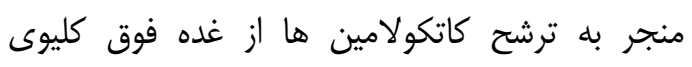
متناسب با شدت فعاليت مى شود(و آ). اين هورمون ها ضربان و انقباض يذيرى قلب را افزايش داده و منجر

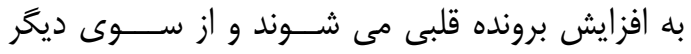

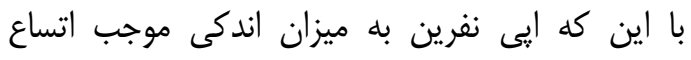

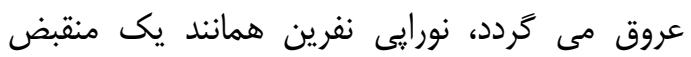

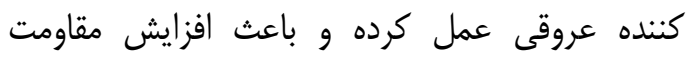

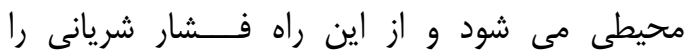

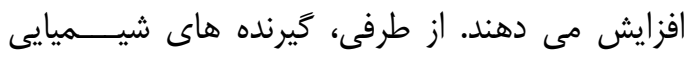

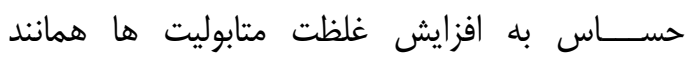
لاكتات و گيرنده هاى مكانيكى حساس به تغيير طول عضله سبب افزايش فشارخون سرخرگى مى شوند (1).

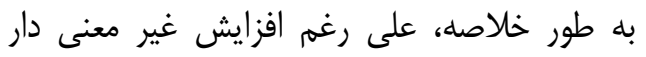

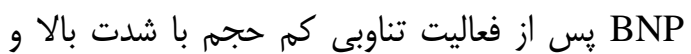
نبود تفاوت در مقادير صبح و عصر اين يِيتيد، ميانكين غلظت BNP در صبح بيشتر بود. با وجود اين كه

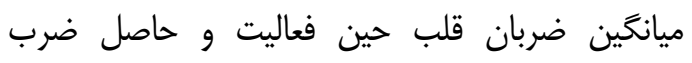

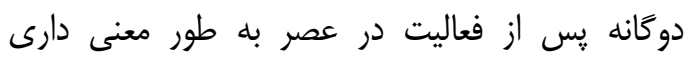
بيشتر از صبح بود، با اين حال به دليل كمتر بودن ميانخين غلظت BNP در عصر به نظر مى رسد فعاليت

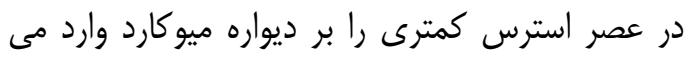
كند و انجام فعاليت ورزشى در عصر مى تواند مناسب

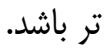

\section{سباسگز ارى}

مطالعه حاضر داراى تايـــيديه اخــــــاقى با كد

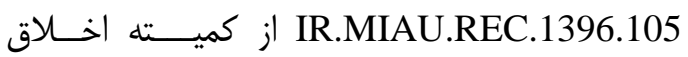
در يزوهش دانشگاه آزاد اسلامى واحد مرودشت مى باشد. ضمناً از كليه دانشجويان تربيت بدنى دانش الشعاه

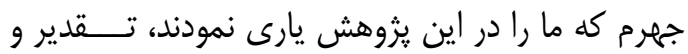
تسشكر مى نماييه.

\section{References}

1.Sudoh T, Kangawa K, Minamino N, Matsuo $\mathrm{H}$. A new natriuretic peptide in porcine brain. Nature 1988;332:78-81. doi:10.1038/332078a0
به دســت آمــــده، محبى و همكاران(سا.+r) در تحقيقى بر روى مردان جوان دونده و شناگر افزايش

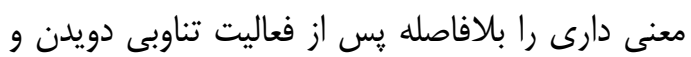

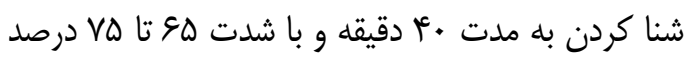

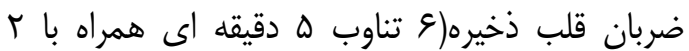
دقيقه استراحت بين هر وهله) مشاهده نكردند(ع). اين تضاد در نتايج حاصل ضرب دوگانه ممكن است به

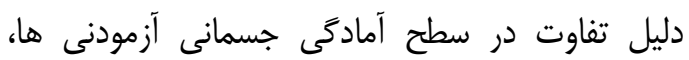
شدت و نوع تمرين باشد. آزمودنى هاى مطالعه محبى و

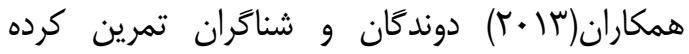

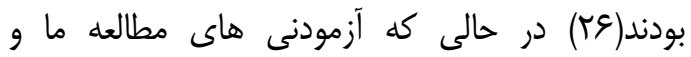
مطالعات همسو را افراد فعال و غير ورزشكار تشكيل

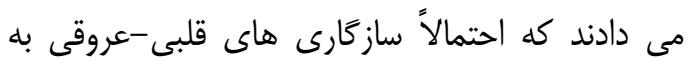
فعاليت ورزشى در تفاوت نتايج نقش دارد. هم جنين،

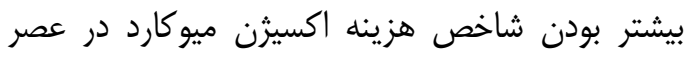

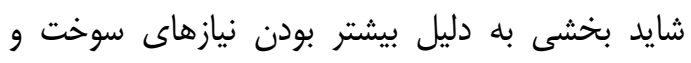

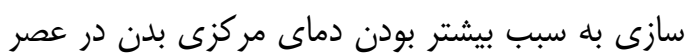

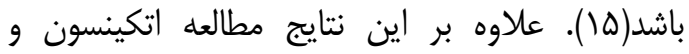
ريلى(999) نشان داد كه ميزان ضربان قلب در ياسخ

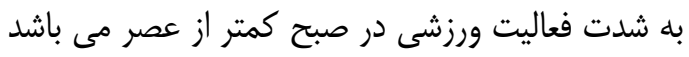
كه با يافته هاى به دست آمده در مطالعه حاضر هم خوانى دارد و همين عامل مى تواند دليلى در تفاوت مشاهده شده در حاصل ضرب دوكانه بين صبح و عصر

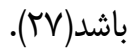

حاصل ضرب دوكانه شاخصى مهم در تعيين گردش خون كرونرى به نيازهاى سوخت و سازى ميوكارد، عملكرد بطن و بار كارى ميوكارد است و و همبستخى نزديكى با اندازه كيرى مستقيم اكسيثرن

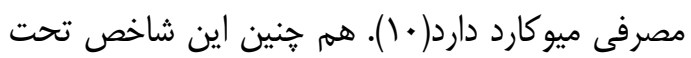

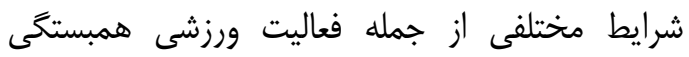
خوبى با اكسيثن مصرفى ميوكارد دارد. ضربان قلب،

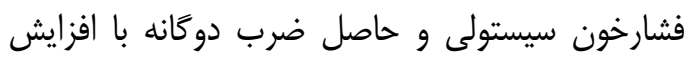
بار كارى قلب، به منظور تامين خون كافى براى عضله

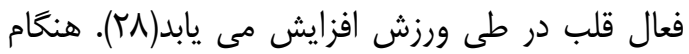

2.Mukoyama M, Nakao K, Hosoda K, Suga S, Saito Y, Ogawa Y, et al. Brain natriuretic peptide as a novel cardiac hormone in humans evidence for an exquisite dual natriuretic 
peptide system atrial natriuretic peptide and brain natriuretic peptide. J Clin Invest 1991 ;87:1402-12. doi: 10.1172/JCI1 15146

3. Yasue H, Yoshimura M, Sumida H, Kikuta $\mathrm{K}$, Kugiyama $\mathrm{K}$, Jougasaki $\mathrm{M}$, et al. Localization and mechanism of secretion of Btype natriuretic peptide in comparison with those of A-type natriuretic peptide in normal subjects and patients with heart failure. Circulation1994;90:195-203.

4.Tanabe K, Yamamoto A, Suzuki N, Akashi Y, Seki A, Samejima H, et al. Exerciseinduced changes in plasma atrial natriuretic peptide and brain natriuretic peptide concentrations in healthy subjects with chronic sleep deprivation. Jpn Circ J1999;63:447-52. doi: $10.1253 /$ jcj.63.447

5.Krupicka J, Janota T, Kasalova Z, Hradec J. Effect of short term maximal exercise on BNP plasma levels in healthy individuals. Physiol Res 2010;59:625-8.

6.Dunham C, Harms CA. Effects of high intensity interval training on pulmonary function. Eur J Appl Physiol2012 ;112:3061-8. doi: 10.1007/s00421-011-2285-5

7.Molmenhansen HE, Stolen T, Tjonna AE, Aamot IL, Ekeberg IS, Tyldum GA, et al. Aerobic interval training reduces blood pressure and improves myocardial function in hypertensive patients. Eur J Prev Cardiol2012 ;19:151-60. doi: 10.1177/1741826711400512

8.McDonagh T, Robb S, Murdoch D, Morton $\mathrm{J}$, Ford I, Morrison C, et al. Biochemical detection of left ventricular systolic dysfunction. Lancet 1998;351:9-13.

9.Scharhag J, George K, Shave R, Urhausen A, Kindermann W. Exercise-associated increases in cardiac biomarkers. Med Sci Sports Exe $2008 \quad ; 40: 1408-15 . \quad$ doi: 10.1249/MSS.0b013e318172cf22.

10.Mcardle WD, Katch FI, Katch VL. Exercise physiology nutrition energy and human performance. $2^{\text {th }}$ ed. Lippincott Williams Wilkins Publication. 2010;P.231-6.

11.Lamotte M, Chevalier A, Jamon A, Brassine E, Borne P. Hemodynamic response of an isokinetic testing and training session. Isokinet Exe Sci 2009;17:135-43. doi: 10.3233/IES-2009-0345

12.Viru AA, Viru M. Biochemical monitoring of sport training. Hum Kin 2001;2:123-7.

13. Ghasemi E, Saghebjoo M, Dadi Z, Maraki $\mathrm{H}$. Effects of one bout of maximum aerobic physical activity in morning and evening on plasma GH and cortisol levels in young female. J Sci Med Sport2012;5:38-47.

14.Kordi MR, Choopani S, Hemmatinafar M, Choopani Z. The effects of six weeks high intensity interval training on resting plasma levels of adiponectin and fat loss in sedentary young women. J Jahrom Uni Med Sci2013;11:23-31.

15.Teo W, Newton MJ, Mcguigan MR. Circadian rhythms in exercise performance implications for hormonal and muscular adaptation. J Sports Sci Med2011;10:600-6.

16.Ohno R, Miyata H, Kimura M. Circadian rhythms and effects of anesthesia on plasma natriuretic peptide levels in rats. Yakugaku Zasshi2009;129:1529-35.

17.Aengevaeren VL, Hopman MT, Thijssen DH, van Kimmenade RR, de Boer M-J, Eijsvogels TM. Endurance exercise induced changes in BNP concentrations in cardiovascular patients versus healthy controls. Int J Cardiol2017 : 15;227:430-5 . doi: 10.1016/j.ijcard.2016.11.016

18.Normandin E, Nigam A, Meyer P, Juneau M, Guiraud T, Bosquet L, et al. Acute responses to intermittent and continuous exercise in heart failure patients. Can $\mathbf{J}$ Cardiol2013;29:466-71. doi: 10.1016/j.cjca.2012.07.001

19.Guimaraes GV, Ciolac EG, Carvalho VO, Avila VM, Bortolotto LA, Bocchi EA. Effects of continuous vs. interval exercise training on blood pressure and arterial stiffness in treated hypertension. Hypertens Res2010;33:627-32. doi: 10.1038/hr.2010.42

20.Sheikhani H, Beygi MAB, Daryanoosh F. Alteration of plasma brain natriuretic peptide level after acute moderate exercise in professional athletes. ICRJ2011;5:148-50.

21.Ohba H, Takada H, Musha H, Nagashima J, Mori N, Awaya T, et al. Effects of prolonged strenuous exercise on plasma levels of atrial natriuretic peptide and brain natriuretic peptide in healthy men. Am Heart J 2001;141:751-8. doi: $10.1067 / \mathrm{mhj} .2001 .114371$

22. Rawlins J, Bhan A, Sharma S. Left ventricular hypertrophy in athletes. Eur $\mathbf{J}$ Echocard2009;10:350-6. 10.1093/ejechocard/jep017.

23. Shahawy M, Entcheva M, Shahawy O, Cohn J. Bnp as a marker for left ventricular hypertrophy in asymptomatic normotensive individuals. Am J Cardiol 2014;63:12.

24.Clerico A, Giannoni A, Vittorini S, Passino C. Thirty years of the heart as an endocrine 
organ physiological role and clinical utility of cardiac natriuretic hormones. Am J Physiol Heart Circ Physiol 2011;301:12-20. doi: 10.1152/ajpheart.00226.2011.

25.Mohebbi H, Rezaei H. [Hemodynamic Responses after resistance, aerobic and concurrent exercise in untrained overweight young Men]. JSSU2014; 22: 989-1001. (Persian)

26.Mohebbi H, Mirzaei B, ShokatiBasir S. Hemodynamic responses after interval running and swimming exercise in trained young men. J Sport Biom Sci 2013;7:75-84.
27.Atkinson G, Reilly T. Circadian variation in sports performance. Sports Med1996;21:292312. doi: 10.1038/sj.jhh.1001377

28.Nagpal S, Walia L, Lata H, Sood N, Ahuja G. Effect of exercise on rate pressure product in premenopausal and postmenopausal women with coronary artery disease. Indian J Physiol Pharmacol2007;51:279-83.

29.Macdonald JR. Potential causes, mechanisms, and implications of post exercise hypotension. J Hum Hypertens 2002;16:22536. doi: $10.1038 /$ sj.jhh. 1001377 


\title{
Acute effects of low-volume high-intensity interval aerobic exercise in the morning and evening on brain natriuretic peptide changes and double product in active men
}

\author{
$\operatorname{Zar} A^{l^{*}}$, Ahmadi $M^{2}$, Ahmadi $F^{2}$
}

(Received: November 23, 2015

Accepted: February 28, 2017)

\begin{abstract}
Introduction: Brain natriuretic peptide (BNP) is an important marker for the evaluation and detection of the left ventricular systolic dysfunction. It seems that physical activity and circadian rhythms are effective in the changes of BNP concentration. Regarding this, the aim of the present study was to investigate the acute effects of low-volume high-intensity interval aerobic exercises in the morning and evening on BNP changes and double product in active men.
\end{abstract}

Materials and Methods: This study was conducted on 11 male physical education students of Jahrom University, Jahrom, Iran. The study population was selected using the purposive sampling technique. The participants were subjected to two separate sessions (with an interval of 3 days) of low-volume high-intensity aerobic exercise in the morning and evening. Blood samples were collected before and immediately after every activity both in the morning and evening. Data analysis was performed in SPSS software (version 17) using independent t-test to compare the mean pretest and posttest upon each session and obtain the mean difference between the morning and evening data. P-value less than 0.05 was considered statistically significant.

Results: The results showed that BNP concentrations increased after exercise in the morning and evening; however, this increase was not statistically significant $(\mathrm{P}>0.05)$. In addition, the results showed that the double product in the morning and evening significantly enhanced after performing the exercises $(\mathrm{P}=0.001)$. There was a significant difference between the BNP concentrations obtained in morning and evening in terms of double product $(\mathrm{P}=0.035)$.

Conclusions: Despite the lack of a significant difference between morning and evening BNP concentrations, due to the lower mean concentration of BNP in the evening, it seems that exercise in the evening exerted less stress on the myocardial wall and could be more appropriate.

Keywords: Brain natriuretic peptide, Double product, Interval aerobic exercise

1. Department of Sport Sciences, Faculty of Literature and Humanities, Jahrom University, Jahrom, Iran

2. Department of Exercise Physiology, Faculty of Physical Education and Sport Sciences, Shahid Chamran University of Ahvaz Ahvaz, Iran

*Corresponding author: Email: salehzar@gmail.com 